\title{
Exploring the Mental Health and Wellbeing Needs of Workers in the UK Automotive Industry
}

\section{Samantha Gellatly}

\author{
Abertay University, UK
}

\begin{abstract}
The purpose of this research was to explore the mental health and wellbeing needs of employees in the automotive sector, to understand the types of initiatives these employees would appreciate and how to promote them effectively.

The research was approached with an exploratory, qualitative design. The collection of employee knowledge and opinion was undertaken utilising in-depth and semi structured interviews with a small cross-sectional group of employees.

The main findings from the research showed that mental health presenteeism and leaveism are commonly occurring. It was found that individual understanding of wellbeing differed due to conflicting terminology and that where the company excelled in the areas of health and safety employees experienced unhappiness with working hours, work life balance and pay and reward.

Research of this scope was original to the company and the automotive sector thus providing great insight. These employees showed there was less need for complex well-being programmes and that there was a keenness for mental health to be recognised and discussed more to help diminish the attached stigma.

This research also questions: who is really best suited to support employee wellbeing? Whilst research highlights the importance of managers in this process, it also confirms, as with this study, that they are the employees with the worst wellbeing and therefore unlikely to be those best suited to provide this support. If managers wellbeing is not boosted it is unlikely that they can bring about desired improvements and bridging this gap requires future consideration.
\end{abstract}

Keywords: Absenteeism; Presenteeism; Mental Health; Wellbeing; Employee Engagement; Automotive Industry

Received: 18 January 2019

ISSN 2056-757X

Revised: 14 March 2019

Accepted: 25 March 2019

https://doi.org/10.18646/2056.61.19-001 


\section{Introduction}

Wellbeing remains a topic at the forefront of research due to the increased awareness of the positive organisational impact that supporting employee wellbeing has on productivity and profitability. This research focussed on wellbeing in one specific company but presented insightful conclusions for the wider sector.

\subsection{The Automotive Industry}

The SMMT (2016) highlight how crucial the automotive industry is to the UK with it averaging a turnover of over $£ 77$ billion, accounting for over $10 \%$ of goods exported from the UK and providing jobs to over 814,000 individuals. For the sector to continue to thrive it is only right that the employees are able to thrive, supporting their mental health and wellbeing thus warrants close attention.

\subsection{Company $X$}

Company $X$ (requesting full anonymity) is a UK SME within the automotive sector. They have 150 employees across a number of sites with an age range from 16 to 70 years, highlighting a large range of potential mental health and wellbeing needs.

Company $\mathrm{X}$ benefit from having relatively low sickness absence levels, however they have observed more recently an increase in longer term absences, particularly in the domain of mental health, mirroring closely the results of other organisations (CIPD 2016a). Based on these observations Company X opted to engage in this research to explore how they could be of further assistance to their employees with these types of concerns. They also wished to understand the aspects of wellbeing most important to their employees to establish ways to improve this also, making wellbeing a more strategic matter.

\subsection{The Concerns}

Research highlights that the concerns being experienced by automotive and manufacturing workers includes musculoskeletal disorders (Spallek et al, 2010) and extended periods of job insecurity which lead to high stress levels (Heaney, Israel and House, 1994). The high physical demands of the work and having little support from co-workers has been found to greatly impact on exhaustion levels (Schnorpfeil, 2002) and those with the lowest earnings in the industry are most likely to have emotional and psychological concerns (French and Zarkin, 1998). These factors all require consideration by employers because high physical workloads, exhaustion and stress, not only lead to errors and reduced work performance but impact negatively on health (Spallek et al, 2010), mental wellness (French and Zarkin, 1998), and increased absenteeism (Fritzche et al, 2014).

International Journal of Management and Applied Research, 2019, Vol. 6, No. 1 


\section{Literature Review}

\subsection{Sickness Absenteeism \& Presenteeism}

Absenteeism has been a cause of concern for a long time due to the cost for organisations and impact on the economy. In 2016 CIPD's survey outlined that the average employee absences totalled 6.3 days per year, costing £522 per employee (CIPD, 2016a) and an estimation of over $£ 100$ billion for the UK as a whole (Black, 2008). The CIPD repeated their survey for 2017 and found that absenteeism had increased slightly to 6.6 days making those cost estimations now even higher (CIPD, 2018b).

Research within the automotive and manufacturing industries has found that absenteeism rates are increased amongst those with lower earnings and emotional concerns (French and Zarkin, 1998). It has also been found that older workers, particularly whose workloads are of an intense physical nature have absenteeism rates that are increased in duration by $25 \%$ and as errors were also found to increase in this group by $80 \%$, due to fatigue, presenteeism is also a relevant concern (Fritzsche et al, 2014).

The idea of presenteeism is a more recent area of research despite it dating further back than absenteeism (Hansen and Anderson, 2008). It is commonly accepted that the cost of presenteeism is greater than absenteeism due to lost productivity (Lack, 2011) but as there can be difficulties in measuring levels of presenteeism (Johns, 2010) it may be difficult to determine the full implications. What certainly isn't wanted is a reduction in sickness absence levels due to an increase in presenteeism levels and so this needs careful monitoring.

As those in the automotive industry, particularly associated with manufacturing, carry out rather repetitive tasks, it is common to see high incidences of musculoskeletal disorders (Spallek et al, 2010). Experiencing pain and difficulty with movement can impact on performance and experiencing pain for prolonged periods of time can have a great impact on mental health and wellbeing, highlighting an area of consideration for employers.

The CIPD's (2018b) latest survey highlights that presenteeism figures have tripled since 2010 with $86 \%$ of companies reporting that they have seen this occurring. Where leaveism is concerned $69 \%$ of those surveyed had observed this occurring and $87 \%$ of people felt they struggled to 'switch off' when outside work due to technology (Burt, 2018). The top causes of short and long term absence featuring both stress and mental health are therefore of no surprise and as these could potentially be addressed, employers are increasingly being encouraged to support mental health and wellbeing within the workplace (CIPD, 2016a).

\subsection{Mental Health and Wellbeing}

Poor mental health experienced at work is affected not just by workplace practices and pressures but also by our own social and personal lives and the balance we strive to

International Journal of Management and Applied Research, 2019, Vol. 6, No. 1 
maintain between these (CIPD, 2016b) and as the boundaries continue to blur, stress and mental health concerns are rising.

Two fifths of organisations reported increases in mental health issues and one third reported increases in stress related issues in 2016. In 2017, over half of organisations reported increases in mental health concerns in the previous year alone, with one fifth of organisations reporting that mental health is the top cause of long term absence (CIPD, 2018a).

Worryingly, only $43 \%$ with poor mental health disclose it to a manager (CIPD, 2016b) highlighting that training in mental health is very important and additionally, nearly half of those surveyed report never taking time off for mental health concerns, but $95 \%$ admit their work has suffered from concentration difficulties. Finally, the $26 \%$ of employees who are unaware of any support their employer could provide, indicates that not just the necessity of supportive absence management but the importance on employers to promote mental health and wellbeing.

To add to these statistics, a recent survey conducted by People Management (Whitehouse, 2018) report that 1 in 4 people believe their work is currently impacting negatively on their mental health with a fifth of people feeling exhausted and a tenth of people feeling miserable. Consistent with the findings of CIPD (2016b), Whitehouse (2018) also show that middle managers experience the greatest level of mental health concerns with this group reporting high levels of pressure and excessive workloads.

Research by Schnorpfeil et al (2002) has identified several factors that are associated with exhaustion in manufacturing workers including; high workloads, adverse physical work conditions, qualification potential, adverse co-worker behaviour and co-worker social support. Similarly, Edimansyah et al (2008) also found that working in hazardous conditions, having limited supervisor support and experiencing high job demand and job insecurity can all increase feelings of depression, anxiety and stress. The identification of these factors could allow those in similar working environments to recognise their areas of concern allowing for early intervention to prevent exhaustion from having greater negative effects on presenteeism and mental health.

It has further been found that experiencing mental health difficulties, on any level, can have additional impact on sickness absence, with employees taking more time off for various other ailments. Thus, it is increasingly important to recognise early on when employees are struggling and offer adequate support as soon as possible (CIPD, 2018a). If we fail to do this mental health concerns will continue to grow, seeing engagement levels plummet, costing companies, the economy and society (CIPD, 2018c).

With mental health and general wellbeing becoming increasingly important and recognised by employers, employees and advocates of better working conditions there are numerous viewpoints describing the aspects they should be focussing on. CIPD, XpertHR and ACAS are merely a small number of these and they place emphasis on

International Journal of Management and Applied Research, 2019, Vol. 6, No. 1 
feeling balance and support within both work and our personal lives to achieve wellbeing in the holistic sense.

Some of the important factors they recommend are focussing on mental health, having good working relationships and ensuring open communication. They emphasise safe working practices, access to training opportunities and fairness and equality. They believe flexible working, appropriate pay and reward elements and adequate policies and practices to promote each of these elements will all support wellbeing. It is important that wellbeing isn't a 'list' but a comprehensive mix of elements that are cemented by a wellbeing strategy that all employees, particularly managers, are reciprocal of (Silcox, 2018; ACAS, 2012; CIPD, 2018a).

The promotion of positive wellbeing has attempted to be addressed by many organisations (CIPD, 2016a) but it has been relatively slow due to some not realising their role in this, the full impact it can have on productivity (PwC, 2008), what exactly they should be implementing and in some circumstances what wellbeing truly encompasses (Low et al., 2016; Spence, 2015; Thomson, 2015).

Some of the more common and straightforward policies that have been implemented in an attempt to support wellbeing include flexible working, job sharing and working from home to generally support a better work-life balance. These can all help to alleviate psychological difficulties as the pressure of work, long hours, and having little control over work are all found to negatively affect wellbeing (Michie and Williams, 2003). It is virtually impossible for all organisations to make such adjustments to working hours or facilitate home-working; however, with Company $\mathrm{X}$ being a prime example, so these types of organisations are encouraged to facilitate wellbeing support via alternative means.

\subsection{Wellbeing Initiatives}

Wellbeing initiatives aim to promote happiness, increase engagement and productivity and reduce absence levels for organisations (CIPD, 2018c).

PwC (2008) report on studies that have had successful outcomes using wellbeing initiatives that targeted physical health and incorporated healthy eating, support to stop smoking and reduced cost exercise programs. The companies implementing these noticed improvements in absence, productivity and profit giving a great deal of support to wellness programmes, but merely focussing on physical health is just the start (CIPD 2016c).

Some companies have gone further and developed strategies that incorporate tools to support mental health such as stress management tools and occupational health support (CIPD, 2016c). More recently, studies have found positive benefits of mindfulness training (Lomas et al., 2017) and resilience training to help enhance productivity and improve wellbeing and mental-health (Sarkar and Fletcher, 2017) and others have even incorporated yoga into their wellbeing programme (CIPD, 2018a). To help provide

International Journal of Management and Applied Research, 2019, Vol. 6, No. 1 
financial support some organisations utilise companies like Perkbox that provide discounts on outings and food to offer extra incentives and benefits (Perkbox, n.d.).

Employee Assistance Programmes (EAPs) are also designed to enhance wellbeing by addressing personal issues and supporting the individual to happiness (Arthur, 2010). They are usually provided by an external agency and have services that are referred for either by a manager or self-referral. The UK Employee Assistance Programme Association provides a list of numerous UK EAPs, many of whom are registered with them, showing their services have met very high standards (EAP Association, 2017).

One specific assistance programme that specialises in providing support to those in the automotive sector is Ben. The support that can be provided by them is considerable and includes physical health and mental health support, social support and financial advice. Ben report that the top three reasons for automotive workers contacting them over 2017-2018 were; low income, anxiety and depression and physical illness, which corresponds with other findings that have been presented. Ben was able to help by providing counselling to 151 individuals and they supported employees to claim over $£ 800,000$ in entitled benefits (Ben, 2019). Ben assist not just employees but also their families and not just during their service within the industry but following it as well, thereby reaching over 1 million UK citizens (Ben, 2017).

The value of EAP's are considerable but there are elements associated directly with the workplace that cannot be managed by an external agency and as EAP's are required when there are already concerns, employers are urged to focus on preventative measures.

Based on the research cited earlier it has been recommended that those within the automotive and manufacturing industries focus their efforts on supporting and reducing musculoskeletal disorders, which have been found to have higher rates amongst trainees and those undertaking new tasks (Spallek et al, 2010). It is also important for those at risk of job insecurity to have support in place to limit the negative emotional effects of this (Edimansyah et al, 2008) and that there are efforts to identify as well as treat mental health and emotional conditions (French and Zarkin, 1998). There is also a clear need to ensure that employees feel supported and that their wellbeing is being taken seriously. They need to have the opportunity to engage in consultation, mentoring and supervision as these factors can prevent feelings of depression and stress (Edimansyah et al, 2008).

Whilst these observations are general to the industry to establish the most beneficial support system for any organisation you must engage your employees in the process and make it suitable for their needs or it may become a costly venture with little benefit (Zoller, 2014; PwC, 2008; Spence, 2015). Even once we establish the mental health and wellbeing needs of our employees we must not forget these can and will change over time and the course of a career. At different stages of our working lives and across generations we need and appreciate different working conditions, incentives

International Journal of Management and Applied Research, 2019, Vol. 6, No. 1 
and rewards relative to our career stage and personal circumstances (Thomson, 2015; Low et al, 2016).

According to Silcox (2018), manual workers are those least likely to engage with wellbeing initiatives; furthermore, as many of those in the automotive industry are in manual roles, more careful consideration as to what is the most appropriate support and how employees can be encouraged to engage with it is likely to be necessary.

Wellbeing is thus a complex endeavour and we must ensure those responsible for promoting and enhancing it, have appropriate training to facilitate this (CIPD, 2016b and Sikora and Ferris, 2014). One of the most crucial elements lies with middle managers, they need to be on board and receptive to the ideas and changes from their managers, they need to understand the benefits and be trained to deliver information consistently and equally. They also have the most valuable insight into their employees and their needs and so can be of great assistance in tailoring packages, making managers very important in creating effective change (Justesen et al, 2017).

To summarise, the increasing incidences of stress and mental health related absenteeism and presenteeism warrants greater attention from employers. Supporting these concerns and all around wellbeing has been shown to improve the happiness, engagement and productivity of employees whilst allowing organisations to benefit from reduced absences and turnover and increased profitability. Not every employee will appreciate every initiative but offering wide ranges and choices can help cater to the majority and boost wellbeing.

\section{Methodology}

This research was undertaken as an exploratory study within Company $\mathrm{X}$ gathering qualitative data consisting of employees' views, opinions and understanding and was of a largely inductive approach.

Nine employees participated in the research. These employees included executives, senior managers, middle managers and non-managerial colleagues. Participants were sampled on a convenience basis, whilst also fulfilling the quota designated by the researcher, ensuring employees within various locations and designations participated.

This research being of an exploratory qualitative nature opted to utilise the nonstandardised methods of both in-depth and semi structured interviews. The board level participant engaged with the in-depth interview and all other employees participated within one of two semi structured question sets. Two sets of questions were used dependant on the designation of the respondent with a set for managers and a set for non-managers.

All interviews were conducted on an individual, face-to-face basis within each participant's place of work and during their working hours ensuring familiarity and

International Journal of Management and Applied Research, 2019, Vol. 6, No. 1 
comfort with their environment, but was also necessary due to working locations and commitments.

Thematic analysis being a highly flexible and accessible means of qualitative data analysis that has been used widely in health and wellbeing research was an ideal tool for the analysis of findings in this research (Braun and Clarke, 2014) and the 6 step approach of Braun and Clarke (2006) was the method utilised.

\section{Data Analysis \& Findings}

Theme 1 - Absenteeism is not a prevalent concern currently, however presenteeism is commonly occurring across the company at all levels.

Finding 1: The reasons for employees coming into work when they are unwell is mainly due to commitment to their teams, although this is not explicitly stated, and secondly for financial reasons.

Where non-managerial and middle managerial employees are concerned the reasons are often the sense of letting their teams down and then monetary related concerns. One employee stated "coming in sick, we all do it, we can't afford to be off. I also feel guilty so I'll come in no matter how ill I am". When presenteeism was discussed at senior managerial levels it was suggested it occurred "not because of how they will be viewed or money but because of how they are" expanded to clarify "it is about the team work, they are small teams and want to support each other". It was clear there is strong respect for fellow colleagues and as such they do not wish to impact extra pressure on one another and absence clearly causes this. The monetary aspect is likely a concern for some due to the provision of only statutory sick pay, the comments suggest however, the monetary factor is a secondary reason behind the impact of supporting your colleagues.

Finding 2: There are likely higher levels of mental health related presenteeism occurring within the company than managers envisaged.

Although examples of mental health related concerns were not directly asked for, many were volunteered with the majority stating they knew someone in the company with such concerns. This indicated that the instances of mental health were likely higher than the company were aware of and highlighted for some individuals it impacted upon their work daily. One employee offered "we have someone [with mental health concerns] and at a certain time every day they would start to struggle. There's nothing in work to support that, there are things in here that make their condition worse". They also mentioned "they would rather tell someone an excuse if they needs to phone in than tell them the truth". The views of senior managers didn't go into such detail but they felt able to recognise "changing behaviour or attitudes" and "would know quickly if anything is wrong". This shows there is recognition of these concerns but whether all employees are open about them and discuss them with managers and not just colleagues, remains unknown.

International Journal of Management and Applied Research, 2019, Vol. 6, No. 1 


\section{Theme 2 - Leaveism is commonly occurring across the company, largely due to the actions of managerial staff.}

Finding 1: Managers are voluntarily contacting branches on their scheduled days off and working out-with work hours although for varying individual reasons.

The acts of leaveism are conducted more by senior managers with one reporting "guilty, when I was on holiday, my phone didn't stop. I have the reporting suite on my phone. I might open up the computer to check emails at night or in the morning" and a second volunteering that "even if I am off I'm likely to phone in the morning and at night. I tell them to call me if they need anything". This is a similar view to middle managers, however their concerns are about the skills the team possess and for senior managers this "it's about welfare".

Finding 2: Leaveism appears to be occurring mainly due to either a lack of communication or a lack of skills within the teams, meaning the team cannot perform adequately in the absence of a manager.

Based on the comments around leaveism it would appear that these acts could largely be avoided due to them mainly concerning poor communication or a lack of skills. According to one middle manager "there needs to be more training, the assistant managers are not up to the same standard [as managers] they should be at the same level but they aren't", this highlights that greater up-skilling of assistant managers needs to be undertaken, supporting managers to have uninterrupted leave. A further middle manager however reports that "I tend to find now I don't get a phone call unless I've forgotten to tell them something. I'll go through and give them a handover the night before, so they know what to expect". This shows good practice and that strong communication can ensure leaveism does not occur quite so readily and is something that can be addressed easily to help support improved wellbeing.

Finding 3: The impact of leaveism differs depending on the role being undertaken, with non-managerial employees reporting a far greater negative impact.

Those in non-managerial positions report a much greater negative impact of being requested to work on their days off, a consensus shared by all those interviewed at this level. There were reports of "it has a very negative impact. You shouldn't be put in that position of having to say no to coming in on your day off" and "I've recently been asked to come in on my days off. I've done my contract you shouldn't ask anymore. It has a negative impact". These views are clearly highlighting that those in nonmanagerial positions are suffering the impact of not receiving allocated days off. To contrast, those in senior managerial positions do not seem to experience the same negative impact of leaveism stating "I enjoy it. It's not impacting on my mental health. I can switch off" and "I am a hypocrite, I encourage them to have their time off. I could take my two days off but I choose not too". Based on these comments senior

International Journal of Management and Applied Research, 2019, Vol. 6, No. 1 
managers could have more influence in how leaveism is occurring across the company but opting not to engage in it themselves.

\section{Theme 3 - There is a lack of awareness being raised and promotion of mental health support from the company.}

Finding 1: Employees are either unaware of any promotion or report there is none and many are unaware of specific support available to them including the charity Ben.

The company admit that they do not currently do anything specific to support mental health and there is no promotion of mental health support. Many of the employees were aware of this with senior managers reporting "no, we don't have anything in place". Middle managers were more uncertain of what the company was doing, they all reported having seen no promotion within the company and then added "I've not come across it much" and "I've not any experience of that in this company". When discussing support that could be accessed externally, many employees were unable to name a source but understood that there were helplines or information online. Only one manager had any knowledge of the charity Ben as an EAP and was due to coming across the organisation whilst employed elsewhere. Despite the lack of promotion of mental health support from the company it is positive that employees do appreciate and are receptive to available support.

Finding 2: Employees share in the opinion that more should be done to support mental health and they are keen for the company to ensure there are greater avenues of support and better communication to aid this.

The senior managers felt that the company should be doing more with suggestions including "spend time having conversations with people and getting a more open culture, asking people if they are ok, understand peoples circumstances and raise awareness with managers about looking after their teams". Non managers also felt "there is never going to be enough help for mental health in our place. I feel it would be a really good thing for a company to do, to put things in place". This is encouraging that these employees are keen to have more support and want to work on ensuring open communication occurs.

Finding 3: There are various means through which the company could successfully promote mental health matters including posters, newsletters and supporting more open communication.

Employees were all receptive to mental health being promoted more around the workplace and offered insight as to how this could best be achieved to maximise awareness. Opinions included; "It's as simple as putting it in a newsletter. Maybe a small course or training to be able to recognise issues". Further suggestions included using "social media or posters" and there were also common views that simply discussing these issues more openly could also be a good way to promote understanding and awareness. One employee offered "just have a chat, just talk about

International Journal of Management and Applied Research, 2019, Vol. 6, No. 1 
it, it's not talked about enough". This highlights that there are various small changes that could be implemented easily to help raise awareness.

\section{Theme 4 - The understanding as to the elements incorporated within wellbeing is varied and could be better supported.}

Finding 1: Employees are all aware of the term wellbeing and can explain its meaning but have differing views as to whether this is addressed in the work place due to the use of different terminology and understanding.

All the employees who were interviewed were confident they had heard the term wellbeing and could easily report what it meant to them but had differing views on whether wellbeing was addressed at work. Senior managers felt it was more of a concept that was considered but not openly addressed. Senior managers felt "it is done but it goes unsaid, we like to look out for others wellbeing but we don't say the term" and "it's more duty of care than wellbeing, that's the terminology I use" The views of non-managerial staff were interesting and in contrast feeling "no, it's not openly discussed". The reasons for this contrast are likely due to terminology and full understanding as to all the elements wellbeing incorporates and also as they feel less of a duty of care than their managers.

Finding 2: Wellbeing concerns are addressed more reactively as they become apparent rather than proactively likely due to the understanding of wellbeing and the lack of formalised policies.

It would appear that rather than have a varied range of wellbeing initiatives in place there is a more reactive approach to dealing with things. This was indicated by middle managers who when asked about wellbeing said "its ad hoc, if anything comes up we would ask the manager and he would see to it, there isn't much more [the company could do for wellbeing]". This has been suggested further by others, reporting "everybody's wellbeing is different, it's individual. I would be able to get that support if I needed it, I voice it and arrange for it to be dealt with". It is positive that employees feel they can ask for support and are confident they would receive it however, there is more that could be done proactively. This reactive view is likely due to the employees feeling health and safety is the main focus of wellbeing and many of the issues within this domain will be dealt with on a more reactive basis.

Finding 3: Employees are motivated by different wellbeing factors with the industry generally appreciating less complex and formal measures, favouring more simple gestures of finishing early or a subsidised meal.

Whilst indicated in the literature that some employees appreciate wellbeing incentives including massages and gym memberships no such ideas were presented by this group of employees with the exception of one. One employee commented "I'm not sure what they could do, give us a gym membership" which although refers to a possible incentive doesn't actually confirm if this would be appreciated or worthwhile

International Journal of Management and Applied Research, 2019, Vol. 6, No. 1 
implementing. A common theme was that small gestures such as receiving a meal paid for was very welcome there were reports of "I buy them their breakfast or lunch, they appreciate that" and "they appreciate early finishes, getting their lunch bought for them, smaller gestures mean a lot". Due to the nature of the long and physical working days, where an hours' unpaid lunch break is rarely received, the best gestures appear to be the smaller ones. It is likely this is helped by the fact that it comes from the manager personally, with no requirement to do so, and is therefore interpreted as true appreciation and not a tokenistic gesture.

\section{Theme 5 - There is a lack of holistic wellbeing support provided by the company.}

Finding 1: There is a strong focus on health and safety and physical health but not across other areas with employee's differing greatly in their views.

It was agreed by everyone that health and safety and physical safety were addressed very well with reports of "it's very important to keep the staff safe, we do everything we can in that sense". When it came to other areas there were more mixed reports with some very contrasting ideas. Whereas one middle manager felt "personal growth is good" due to training and progression opportunities offered to them, another contrastingly felt "I don't think there is anything that jumps out that we are really good at, there is no career development". The belief that the company are doing very little to address some areas are likely down to individual needs and preferences not being met and are unlikely to be the collective views of the company, but it highlights there are still improvements that could be made.

Finding 2: The areas requiring the greatest input and having the most negative impact at present include working hours, work life balance, pay and reward and communication and training opportunities.

The managers offered much more varied responses as to what aspects of wellbeing were in the greatest need of being addressed but there were certainly common themes appearing. Reports included "the hours can be long and they can work quite late, we have no EAP [employee assistance programme], conflict resolution training, training in difficult conversations is not something we have and we don't discuss stress management". A second senior manager offered a collection of rather different thoughts suggesting "we have never created a creative culture. They should be creative and think outside the box". These are interesting thoughts and show there isn't just potential improvements to the direct wellbeing of the employees but by looking at the way the organisation conducts its business, there could be an indirect impact on the employees' wellbeing through the success they feel. For others negative aspects related to work hours and pay, reporting "issues are not getting a dinner break, one hour is docked per day for lunch, but the hour is not received" and "I'm not understanding the bonus yet and how to maximise it". Insight into improving reward was also offered with "wee things go a long way, competitions would be good, they get you going". For another middle manager the main elements were communication and pay and reward feeling 'I'm fairly paid but it's not very transparent sometimes. He felt a lack of

International Journal of Management and Applied Research, 2019, Vol. 6, No. 1 
consultation with regards to his branch performance and further reported that "work life balance can be negative, but if you need time off there is some flexibility with the rota". Finally, the views of a non-managerial employee included "there's slow processes, they could listen to us more, you can say things in passing but the manager doesn't come round and ask how we could do things better". These statements although varied show some generalisations and also confirm that no complex incentive systems are required. Whereas it is unlikely that working hours or pay can be addressed to any extent, aspects such as communication and training opportunities can be tackled.

Finding 3: Those experiencing the poorest wellbeing at present are managers as they are being given the least support.

Given the evidence presented earlier regarding managers feeling more stressed and the negative impact of work for this group it is unsurprising that they are reporting some of the poorest wellbeing. Where non-managerial employees were concerned they believed "my wellbeing at work is very good". Where middle managers were concerned they reported "I don't think mine [wellbeing] is good. I feed back to my team but I don't receive feedback", with reports from senior managers including "my wellbeing is the bottom of the scale at the moment. My workload has increased a lot recently and I put the guys in front of me in terms of what they need". Even at board level there were views of "I'm supported with regards to the job but not necessarily with wellbeing" highlighting that managers are filtering so much down to other employees that they are neglected of their own wellbeing.

\section{Theme 6 - The organisational culture is supportive to making improvements regarding mental health and wellbeing.}

Finding 1: Employees report having good line management, who are receptive to change and open and approachable.

For employees to be able to disclose any concerns or issues they need to feel that their line mangers are approachable and supportive. The majority of employees all reported that this was the case and not just with their managers but with their wider teams also. Reports included; "I can speak to my [line] manager and we have got a good senior manager, he is approachable". "We have regular group chats in the mornings, we can voice concerns". This was also agreed by middle managers regarding their line managers with employees stating; "If I need my manager I know where they are" and "we're taken care of if we need anything". Even at senior managerial level there are similar positive reports which highlight strong, open channels of communication that support wellbeing and mental health being addressed and this is crucial.

Finding 2: Employees believe everyone is instrumental in improving mental health and wellbeing. Individuals need to open up as well as having supportive systems throughout the organisation.

International Journal of Management and Applied Research, 2019, Vol. 6, No. 1 
A large emphasis is placed upon the importance of line managers in the implementation of policies and strategies, however when it comes to mental health and wellbeing there is a general consensus amongst these employees that everyone has a responsibility to support improvements. All non-managerial employees agreed that it was a universal effort with reports of "everyone, the individual needs to open up", "everybody, start further up and work down. Have everyone on board". Managers felt more personal responsibility with supporting their colleagues whilst also acknowledging the collective effort required with reports of "the managers [should be responsible] but individuals have a responsibility also". These comments are encouraging and show a good understanding as to the responsibilities we have in looking after wellbeing. Again, the strong sense of team membership is driving these employees to appreciate the need for a collective effort, where everyone supports one another.

Finding 3: Employees are keen to banish the stigma surrounding mental health and changing the mentality of those working in the industry.

There have been concerns that in the industry mental health is not talked about openly and carries a stigma preventing people from opening up about any problems and this is certainly acknowledged by some of the employees across levels. One employee, also relatively new to the industry, reported that "this workplace has a different mentality, I would like to see more openness and honesty within the culture" with this being agreed by a further report of "it's a lot less talked about in our environment". Some of the employees were very passionate about this changing however with comments including "we have to get around the stigmatism, we have to get past the 'you're a mechanic you should be hard skinned' you shouldn't have to just deal with it or take it". This is very encouraging and highlights that employees are receptive to changing the misconceptions people have and improving avenues for discussing mental health, so all employers should embrace discussing these issues.

Finding 4: Employees are open to additional training opportunities not just related to the mechanical aspects of the role.

Senior managers were open to training opportunities after revealing the lack of formal training within this company for absence concerns or mental health. Managers reported "I've no official training but any training would be beneficial" and "yes previously I have had training on absence but mental health, probably not". The views on training were shared by all managers with them all identifying different areas in which they would appreciate training including "training for line managers, sickness absence management, conflict resolution and training in difficult conversations". There were also comments regarding mental health including "I've no problem speaking to anyone about [mental health] these things, but do you not need to be qualified"? This idea of requiring specific mental health qualifications was also shared by others. This highlights that training within mental health to support awareness and understanding would be very beneficial and would support managers in looking after their teams' wellbeing.

International Journal of Management and Applied Research, 2019, Vol. 6, No. 1 
The main findings that have emerged from this research are that presenteeism and leaveism are commonly occurring and are enhanced through managers' actions. Mental health awareness and promotion were found to be lacking with employees receptive and keen for more to be done to support and promote mental health. The organisational culture is thus very positive and could nurture mental health awareness with open channels of communication, good line management and people willing to have a better understanding, helping to dispel any stigma remaining. Finally, wellbeing was found to have mixed views as to what it incorporated and what the company were doing well. It was generally felt that there was a heavy focus on areas such as physical safety whilst neglecting others, including communication and creativity. This highlights that Company $\mathrm{X}$ has areas to address to ensure they are providing a holistic approach to ensuring all of their employee's wellbeing is being addressed.

\section{Discussion and Recommendations}

Based on the findings of the research, mental health absenteeism was positively not of great concern for Company X. However, reference was made to an individual who has taken time off and not reported that it was due to a mental health concern, highlighting more absences may be mental health related than realised. This supports CIPD (2016b) research showing $43 \%$ with poor mental health do not disclose their concerns to a manager, leading to incorrect identification of absence issues and inadequate or inappropriate support being offered, which is a concern.

The research did find a high prevalence of mental health related presenteeism with a number of employees recognising their colleague's struggles in the workplace, showing that levels of this are also likely higher than appreciated. This also supports CIPD (2016b) reporting that half of those with mental health concerns don't take time off work but for $95 \%$ their performance is negatively affected. Meaning there is a great impact on productivity and profitability.

In terms of leaveism, People Management (2018b) reported 69\% of organisations encountered this. In Company $\mathrm{X}$ this was higher, as those interviewed all reported this occurring. The previous research also reported $87 \%$ of managers felt they struggled to switch off outside work, the information gathered in this research suggested that leaveism wasn't a struggle for managers as they voluntarily engaged in this activity. However, they are also the group who report the worst wellbeing so on further analysis, it is likely having a bigger impact than they report, but it is not being attributed to affecting mental health.

The employees also offered various ways in which they would appreciate support. A senior manager reported that there was currently no EAP and employees were largely unaware of support that the company could provide highlighting that CIPD (2016b) research suggesting that $26 \%$ of employees are unaware of support that the company can provide, is also higher. It is therefore recommended that the support and services of the charity Ben are utilised by the company as an EAP to ensure that physical health

International Journal of Management and Applied Research, 2019, Vol. 6, No. 1 
needs such as musculoskeletal issues, highlighted as a concern by Spallek et al (2010) are addressed and that mental health awareness is promoted to provide employees with the support they require.

Few managers had reported having had training in either mental health or in absence management and certainly not within their current roles, highlighting an avenue where training would be beneficial and is recommended by both CIPD (2016b) and Sikora and Ferris (2014). A bank of eLearning modules would also be of benefit and cost effective and could extend to include customer service skills, leadership skills and conflict resolution to cater to all employees. This ensures the constant upskilling of the team whilst supporting engagement and retention.

Working hours, work life balance and pay and reward were raised frequently and typically incorporated similar elements. Employees' felt the hours were long and they were often lengthened by being asked to work later or come in on a day off. This was having a negative impact particularly on non-managerial employees, supporting the negative effects of long working hours and poor work life balance Michie and Williams (2003) found and the effects of low earnings on emotional concerns that French and Zarkin (1998) found. This could be addressed through a half day overtime option rather than offering only a whole day, to support work-life balance, and any overtime at the end of the day should be paid at 15 or 30 minute intervals. This would support employees to feel more rewarded and appreciated and positively impact on wellbeing.

There were also further suggestions made regarding working patterns and annual leave. These suggestions varied significantly and support the research by Thomson (2015) and Low et al (2016) that our needs change over time and everyone appreciates different rewards and incentives. It is virtually impossible to cater to everyone and the desired rewards will not always be financially feasible or appropriate.

Having a range of supportive company policies including absence management, whistleblowing, grievance, harassment and a comprehensive wellbeing policy will also be beneficial. This will support employees understanding of the terminology, which was found to impact on wellbeing understanding during the research, and the types of support that are available and will further ensure equality when dealing with these matters.

Further ways employees may be supported is in ensuring the company instil a culture of openness and enhance their channels of communication. Most employees reported that not enough could be done to support mental health and many of those were keen to see open discussion as a promotion for mental health. Employees already felt they could approach their managers and that they had strong social support within the teams, which Schnorpeil et al (2002) and Edimansyah et al (2008) outline as a protective mechanism from experiencing mental health concerns and this may support the lower mental health absence rates in Company X. However, there were no formal procedures in place for consultation to occur and only informal supervision currently

International Journal of Management and Applied Research, 2019, Vol. 6, No. 1 
takes place. This can be addressed through team meetings or an employee forum, and in formalising the supervision process and ensuring employees have a mentor they can establish a positive relationship with. A structured induction that includes discussions about mental health, available support and company policies is also an effective means of raising awareness and ensuring social and managerial support is maximised.

Generally, the employees' views were that more simple measures would have the most desirable outcomes for them, helping to prevent increases in mental health related absenteeism and presenteeism. PwC (2008) reported on organisations that had positive impacts when implementing healthy eating, discounted gym memberships and smoking cessation. Aspects like this were not addressed by employees here however. As Silcox (2018) report that manual workers are those least likely to engage in wellbeing initiatives it would suggest that there is a reluctance to do so however, this research has showed that manual workers are willing to engage with initiatives particularly that support mental health. This research thus offers more support to Zoller (2004), PwC (2008) and Spence (2015) who report that incentives must be relevant or they will not be engaged with and gym memberships and massages are not desirable to this employee group.

To summarise, this research has supported the majority of the literature presented and has found that the wellbeing initiatives that will help to support improvements in mental health related presenteeism include; greater training for managers, open channels of communication and avenues for consultation, access to an EAP, a range of supportive company policies and improvements in working hours and pay and reward.

The research findings offered various means by which promotion of wellbeing initiatives could also be supported and mirror practical suggestions made by Silcox (2018). With the absence in Company X of an organisational intranet and no current use of video screens, employees were most in favour of posters and newsletters to signpost mental health support. There was also the suggestion of utilising social media and emails or writing to employees with information. Whilst sending letters has cost implications there are free options available from the charity Ben that include internet banners, posters and wallet size cards. An email signature with reference to support would also be of benefit to those issued with company email addresses and also has no cost. Although time consuming to produce, a newsletter that is emailed to branches for discussion amongst teams would also provide an avenue of promotion of mental health and wellbeing support and other company initiatives. As social media was also deemed a possibility for promoting mental health support it is recommended the company utilise a Facebook or Twitter page to post or share messages from Ben or Mind or similar charities highlighting the support they offer. This would also support the senior manager's view that the company could move forward with the times, which today, incorporates a high use of technology and media.

As employees expressed that mental health should be talked more about it is recommended that this is facilitated through team meetings, one to one sessions and supervisions and at return to work meetings. There may also be opportunity for

International Journal of Management and Applied Research, 2019, Vol. 6, No. 1 
consultation and open communication to be facilitated through an employee forum, recruiting volunteers to bring ideas forward. This would help address the creativity aspect that senior managers felt was currently lacking. It would support employees to feel heard and respected for their ideas and provide them a degree of autonomy.

Whilst the framework of initiatives and promotion ideas outlined provide a good basis for supporting mental health and wellbeing there are further considerations that need to be made and not just with regards to Company $\mathrm{X}$ but any organisation in any sector.

There is an emphasis placed on managers and their role in understanding, interpreting and supporting mental health and wellbeing needs in their employees (CIPD, 2018a; Justesen et al., 2017; Sikora and Ferris, 2014), but we are failing to appreciate their poor wellbeing when adding these additional role requirements. Can a group of employees who have described themselves as already overstretched, miserable and having the poorest wellbeing really be those best suited to offering increased support to others? Managers feel a responsibility to their employee's, but without the time and resources and positive wellbeing themselves, there is the danger they may neglect to do anything about wellbeing, or that with the increased task load their own wellbeing could suffer even more.

Company X employees feel it should be a collective effort to promote mental health and if managers are not on board, have limited time to implement initiatives successfully or are not personally well enough, it doesn't matter how great the initiatives are, they will be ineffective. Future consideration thus needs to be given to both, how manager's wellbeing can be increased and who is in the best position to be managing employees wellbeing needs.

\section{Conclusion}

This research contributes to the literature in several ways. First, the results of this research are consistent with earlier studies that wellbeing initiatives will require involvement from the outset of design through to implementation, to ensure they will be of benefit and engaged with. Of interest in this research was the complexity of the wellbeing programme required by the organisation, whereas other companies have reported benefits of massages, gym memberships and yoga, Company $\mathrm{X}$ expressed the desire for far more humble suggestions, showing that smaller more personal gestures are more appreciated, a view that likely extends to similar organisations.

This research has thus provided great insight not just for Company $\mathrm{X}$ but the wider industry and is a reminder of the individual nature of wellbeing and that you can only enhance it by knowing your employees and involving them in designing a wellbeing strategy that is relevant for them. It further shows the increased understanding and acknowledgement of mental health concerns and the desire for these to be more openly recognised and discussed. If employers can support the openness and disclosure of such concerns they may significantly reduce absenteeism and presenteeism concerns and contribute to a society more accepting of such conditions.

International Journal of Management and Applied Research, 2019, Vol. 6, No. 1 
The overall results show that there are positive actions that Company $\mathrm{X}$ can take to make improvements in well-being for their employees. These include implementing more formalised policies and promoting an EAP. Ensuring a greater variety of training including within mental health and well-being, that are both classroom and e-learning based. Establishing more open channels of communication and consultation by formalising induction, mentoring and supervision and establishing an employee forum. Finally, making small changes to pay and reward elements would support employees both financially and in terms of work life balance.

The limitations to the research include the following: small sample size and only employees from one region being available, and thus the results may not generalizable to automotive workers at other organisation or country. Company X, if implementing any of these strategies should therefore ensure they review them regularly to make sure they are still relevant and also analyse their impact so they can determine what aspects are truly supporting wellbeing.

The pertinent question is who is actually best suited to taking on this task. There is an emphasis on managers having a lead role, but as the finding indicate, managers are the group with the worst wellbeing and until we can adequately address that, it is an unrealistic expectation that they can fulfil this duty effectively and is a consideration that is currently being neglected.

Future research should thus focus on how manager's wellbeing can be boosted, so that organisations can take the appropriate steps to address this. Research should also be done to examine the results that different groups or individuals attempting to enhance wellbeing and mental health achieve. Determining whether wellbeing champions with a personal interest in wellbeing have more success than managers, or HR in obtaining results would further support organisations to focus their resources and achieve the best results.

\section{References}

1. Advisory, Conciliation and Arbitration Service (ACAS) (2012), Health, Work and Wellbeing [Online] Available from: http://www.acas.org.uk/media/pdf/8/n/Healthwork-and-wellbeing-accessible-version.pdf [Accessed on 10 July 2018]

2. Arthur, A. A. (2000), "Employee assistance programmes: The emperor's new clothes of stress management?", British Journal of Guidance \& Counselling, Vol. 28, No. 4, pp. 549-559. https://doi.org/10.1080/03069880020004749

3. Ben (2017), Impact Report 2016-17 [Online] Available from: http://ben.org.uk/wpcontent/uploads/2017/06/Ben-Impact-Report-201617-web.pdf [Accessed: 15 June 2018]

International Journal of Management and Applied Research, 2019, Vol. 6, No. 1 
4. Ben (2019), Impact Report 2017-2018 [Online] Available from: https://ben.org.uk/wp-content/uploads/2018/07/Impact-Report-2017-18.pdf [Accessed on 11 March 2019]

5. Black, C. (2008), Working for a Healthier Tomorrow: Dame Carol Black's review of the health of Britain's working age population, London: Stationery Office.

6. Braun, V. and Clarke, V. (2006), "Using Thematic Analysis in Psychology", Qualitative Research in Psychology, Vol. 3, No. 2, pp. 77-101. https://doi.org/10.1191/1478088706qp063oa

7. Braun, V. and Clarke, V. (2014), "What Can Thematic Analysis Offer Health and Wellbeing Researchers?", International Journal of Qualitative Studies on Health and Wellbeing, Vol. 9, No. 1, https://doi.org/10.3402/qhw.v9.26152

8. Burt, E. (2018), "Britain's Presenteeism Crisis", People Management, 24 May. [Online] Available from: https://www.peoplemanagement.co.uk/longreads/articles/britain-presenteeism-crisis [Accessed on 6 June 2018]

9. Chartered Institute of Personnel and Development (CIPD) (2016a), Absence Management Survey [Online] Available from: https://www.cipd.co.uk/Images/absence-management 2016 tcm18-16360.pdf [Accessed on 6 June 2018]

10. Chartered Institute of Personnel and Development (CIPD) (2016b), Employee Outlook - Focus on Mental Health [Online] Available from: https://www.cipd.co.uk/Images/employee-outlook 2016-focus-on-mental-healthin-the-workplace_tcm18-10549.pdf [Accessed on 7 June 2018]

11. Chartered Institute of Personnel and Development (CIPD) (2016c), Policy ReportGrowing the health and well-being agenda: From first steps to full potential [Online] Available from: https://www.cipd.co.uk/Images/health-well-beingagenda_2016-first-steps-full-potential_tcm18-10453.pdf [Accessed on 15 May 2018]

12. Chartered Institute of Personnel and Development (CIPD) (2018a), Health and Well-Being at Work [Online] Available from: https://www.cipd.co.uk/Images/health-and-well-being-at-work_tcm18-40863.pdf [Accessed on 3 April 2018]

13. Chartered Institute of Personnel and Development (CIPD) (2018b), Health and Well-Being at Work: Private Sector [Online] Available from: https://www.cipd.co.uk/Images/health-and-well-being-private-sectorsummary_tcm18-41308.pdf [Accessed on 28 May 2018]

International Journal of Management and Applied Research, 2019, Vol. 6, No. 1 
14. Chartered Institute of Personnel and Development (CIPD) (2018c), Well-Being at Work [Online] Available from: https://www.cipd.co.uk/knowledge/culture/wellbeing/factsheet [Accessed on 12 June 2018]

15. EAP Association (2017), Find an EAP provider [Online] Available from: https://www.eapa.org.uk/find-an-eap-provider/ [Accessed: 18 June 2018]

16. Edimansyah, B.A., Rusli, B.N., Naing, L., Mohamed Rusli, B.A, Winn, T. and Tengku Mohamed Ariff, B.R.H. (2008), "Self-peprceived depression, anxiety, stress and their relationships with psychosocial job factors in male automotive assembly workers", Industrial Health, Vol. 46, No. 1, pp. 90-100.

https://doi.org/10.2486/indhealth.46.90

17. French, M.T. and Zarking, G.A. (1998), "Mental Health, Absenteeism and Earnings at a Large Manufacturing Worksite", The Journal of Mental Health Policy and Economics, Vol. 1, No. 4, pp. 161-172. https://doi.org/10.1002/(SICI)1099-176X(199812)1:4\%3C161::AID-

MHP21\%3E3.0.CO;2-I

18. Fritzsche, L., Wegge, J., Schmauder, M., Kliegel, M. and Schmidt, K-H. (2014) "Good ergonomics and team diversity reduce absenteeism and errors in car manufacturing", Ergonomics, Vol. 57, No. 2, pp. 148-161. https://doi.org/10.1080/00140139.2013.875597

19. Hansen, C.D. and Anderson, J.H. (2008), "Going ill to work - What personal circumstances, attitudes and work-related factors are associated with sickness presenteeism?", Social Science and Medicine, Vol. 67, No. 6, pp. 956-964. https://doi.org/10.1016/j.socscimed.2008.05.022

20. Heaney, C.A., Israel, B.A. and House, J.S. (1994), "Chronic job insecurity among automobile workers: Effects on job satisfaction and health", Social Science Medicine, Vol. 38, No. 10, pp 1431-1437. https://doi.org/10.1016/02779536(94)90281-X

21. Johns, G. (2010), "Presenteeism in the workplace: A review and research agenda", Journal of Organisational Behaviour, Vol. 31, No. 4, pp. 519-542. https://doi.org/10.1002/job.630

22. Justesen, J.B., Eskerod, P., Reffstrup, J. and Sjogaard, G. (2017), "Implementing workplace health promotion - role of middle managers". International Journal of Workplace Health Management, Vol. 10, No. 2, pp. 164-178, https://doi.org/10.1108/IJWHM-04-2016-0030

23. Lack, D.M. (2011), "Presenteeism Revisited - A comprehensive Review", Workplace Health and Safety, Vol. 59, No. 2, pp. 77-91. https://doi.org/10.1177/216507991105900205

International Journal of Management and Applied Research, 2019, Vol. 6, No. 1 
24. Lomas, T., Medina, J.C., Ivtzan, I., Rupprecht, S., Hart, R. and Eiroa-Orosa, F. (2017) 'The impact of mindfulness on wellbeing and performance in the workplace: An inclusive systematic review of the empirical literature', European Journal of Work and Organisational Psychology, Vol. 26, No. 4, pp. 492-513. https://doi.org/10.1080/1359432X.2017.1308924

25. Low, C.H., Bordia, P. and Bordia, S. (2016), "What do employees want and why? An exploration of employees' preferred psychological contract elements across career stages", Human Relations, Vol. 69, No. 7, pp. 1457-1481. https://doi.org/10.1177/0018726715616468

26. Michie, S and Williams, S. (2003), "Reducing work related psychological ill health and sickness absence: a systematic literature review", Occupational and

Environmental Medicine, Vol. 60, No. 1, pp. 3-9.

https://doi.org/10.1136/oem.60.1.3

27. Perkbox (n.d.), Our Story [Online] Available from: https://www.perkbox.com/uk/our-story [Accessed on 16 June 2018]

28. PricewaterhouseCoopers (PwC) (2008), Building the case for wellness [Online] Available from:

https://assets.publishing.service.gov.uk/government/uploads/system/uploads/attach ment data/file/209547/hwwb-dwp-wellness-report-public.pdf [Accessed on 16 May 2018]

29. Sarkar, M. and Fletcher, D. (2017), "How resilience training can enhance wellbeing and performance", in: Crane, M.F. (ed.), Managing for resilience: A practical guide for employee wellbeing and organizational performance, London: Routledge, pp. 227-237. https://doi.org/10.4324/9781315648033-14

30. Schnorpfeil, P., Noll, A., Wirtz, P., Schulze, R., Ehlert, U., Frey, K. and Fischer, J.E. (2002), "Assessment of exhaustion and related risk factors in employees in the manufacturing industry - a cross-sectional study", International Archives of Occupational and Environmental Health, Vol. 75, No. 8, pp 535-540. https://doi.org/10.1007/s00420-002-0369-6.

31. Sikora, D.M and Ferris, G.R. (2014), "Strategic Human Resource Practice Implementation: The Critical Role of Line Management", Human Resource Management Review, Vol. 24, No. 3, pp. 271-281. https://doi.org/10.1016/j.hrmr.2014.03.008

32. Silcox, S. (2018) Wellbeing: Good Practice Manual. [Online] Available from: https://www.xperthr.co.uk/good-practice-manual/wellbeing/111425/ [Accessed: 10 July 2018]

International Journal of Management and Applied Research, 2019, Vol. 6, No. 1 
33. SMMT (2016), UK Automotive. [Online] Available from: https://www.smmt.co.uk/industry-topics/uk-automotive/ [Accessed on 3 April 2018]

34. Spallek, M., Kuhn, W., Uibel, S., van Mark, A. and Quarcoo, D. (2010), "Workrelated musculoskeletal disorders in the automotive industry due to repetitive work - implications for rehabilitation”, Journal of Occupational Medicine and Toxicology, Vol. 5, No. 6, pp. 1-6. https://doi.org/10.1186/1745-6673-5-6

35. Spence, G.B. (2015), "Workplace well-being programmes: If you build it they may NOT come...Because it's not what they really need!", International Journal of Well-Being, Vol. 5, No. 2, pp. 109-124. https://doi.org/10.5502/ijw.v5i2.7

36. Thomson, A.B. (2015), “The Intangible Things Employees Want from Employers", Harvard Business Review, [Online] Available from: https://hbr.org/2015/12/the-intangible-things-employees-want-from-employers [Accessed on 2 April 2018]

37. Whitehouse, E. (2018) "One in Four say Work is Hurting Mental Health", People Management, 26 April [Online] Available from: https://www.peoplemanagement.co.uk/long-reads/articles/work-hurting-mentalhealth [Accessed on 6 June 2018]

38. Zoller, H.M. (2004), "Manufacturing health: employee perspectives on problematic outcomes in a workplace health promotion initiative", Western Journal of Communication, Vol. 68, No. 3, pp. 278-301. https://doi.org/10.1080/10570310409374802

International Journal of Management and Applied Research, 2019, Vol. 6, No. 1 